\title{
Seasonal variation in geographical access to maternal health services in regions of southern Mozambique
}

\author{
Prestige Tatenda Makanga ${ }^{1,2^{*}}$, Nadine Schuurman ${ }^{1}$, Charfudin Sacoor $^{3}$, Helena Edith Boene ${ }^{3}$, \\ Faustino Vilanculo ${ }^{3}$, Marianne Vidler ${ }^{4}$, Laura Magee ${ }^{5}$, Peter von Dadelszen ${ }^{5}$, Esperança Sevene ${ }^{3}$, \\ Khátia Munguambe ${ }^{3}$ and Tabassum Firoz ${ }^{6}$
}

\begin{abstract}
Background: Geographic proximity to health facilities is a known determinant of access to maternal care. Methods of quantifying geographical access to care have largely ignored the impact of precipitation and flooding. Further, travel has largely been imagined as unimodal where one transport mode is used for entire journeys to seek care. This study proposes a new approach for modeling potential spatio-temporal access by evaluating the impact of precipitation and floods on access to maternal health services using multiple transport modes, in southern Mozambique.

Methods: A facility assessment was used to classify 56 health centres. GPS coordinates of the health facilities were acquired from the Ministry of Health while roads were digitized and classified from high-resolution satellite images. Data on the geographic distribution of populations of women of reproductive age, pregnancies and births within the preceding 12 months, and transport options available to pregnant women were collected from a household census. Daily precipitation and flood data were used to model the impact of severe weather on access for a 17-month timeline. Travel times to the nearest health facilities were calculated using the closest facility tool in ArcGIS software.

Results: Forty-six and 87 percent of pregnant women lived within a 1-h of the nearest primary care centre using walking or public transport modes respectively. The populations within these catchments dropped by 9 and $5 \%$ respectively at the peak of the wet season. For journeys that would have commenced with walking to primary facilities, $64 \%$ of women lived within $2 \mathrm{~h}$ of life-saving care, while for those that began journeys with public transport, the same 2-hour catchment would have contained $95 \%$ of the women population. The population of women within two hours of life-saving care dropped by $9 \%$ for secondary facilities and 18\% for tertiary facilities during the wet season.

Conclusions: Seasonal variation in access to maternal care should not be imagined through a dichotomous and static lens of wet and dry seasons, as access continually fluctuates in both. This new approach for modelling spatiotemporal access allows for the GIS output to be utilized not only for health services planning, but also to aid near real time community-level delivery of maternal health services.
\end{abstract}

Keywords: Maternal health services, Geographical access to care, Global health, Health geography, Geographical information systems

\section{Background}

Geographical proximity to health facilities is a known determinant of both access to maternal care [1-3] and

\footnotetext{
*Correspondence: pmakanga@sfu.ca

1 Department of Geography, Simon Fraser University, RCB7106 8888

University Drive, Burnaby, BC V5A156, Canada

Full list of author information is available at the end of the article

Full ist of author information is available at the end of the article
}

better maternal outcomes $[4,5]$. These improved outcomes have been attributed to improved access and utilization of antenatal care, as well as of delivery in health facilities that have skilled birth attendants [6-8].

Quantifying geographic access to care is the most common use of geographical information systems (GIS) in maternal health research and practice $[9,10]$. The 
information obtained can aid in the planning and design of health services by evaluating the geographic reach of the health system to its intended population [11], and showing how underserved regions can be reached [12]. GIS modelling of access to care requires information about the location of health facilities, the geographic distribution of populations [13], and how the population moves to access care.

There is a dearth of research on spatio-temporal modelling that incorporates the component of time to account for changes in access during seasons. This is relevant for all places that are prone to severe weather, and is particularly relevant to sub-Saharan Africa where substantial rainfall and flooding in the wet seasons affect the accessibility of roads at very grand scales $[14,15]$. Whether or not these reduced levels of access to facilities may be associated with the seasonal nature of some severe maternal morbidities (such as eclampsia) in tropical climates is unclear [16, 17]. Although women may become sicker in the wet season and attend care later $[16$, 17], it is clear that these women need emergency obstetric care when it is least likely to be accessible.

Many of the models for potential spatial access to maternal care have been developed in high-income settings and cannot be applied directly to low-income regions. For example, in high-income settings, the 1-h driving time threshold is used as a gold standard for identifying populations that are underserved by the health care system. While a $1-\mathrm{h}$ travel time to care is clinically important in high- or low-income settings, many people in sub-Saharan Africa do not drive cars to access maternal care services [15]. Many women usually in sub-Saharan Africa walk to health centres, or use public transport which represents a mix of walking and driving modes $[18,19]$. Furthermore, most of the models for quantifying spatial access to maternal care have not accounted for the impact of seasonality on impeding access to maternal care services. One such study from sub-Saharan Africa [14] presented results in the form of static maps, making it difficult to ascertain how the results could be operationalized and incorporated into health promotion programs that reflect the daily experiences of women as they travel to seek care.

This study aimed to extend current models for access to maternal care services by accounting for the impact of flooding and precipitation, making them more relevant for a typical low- or middle-income country context. We developed a spatio-temporal model to describe how women of reproductive age in regions of southern Mozambique (Fig. 1) would potentially access all maternal health care services, by various modes of transport, and how that access may change during different seasons. Mozambique has reported estimates for Maternal
Mortality Ratio (MMR) that range from 249 to 480 deaths per 100,000 live births, and is among the top 20 countries with the highest MMRs in the world [20-22]. There has been between 50 and 63\% reduction in MMR from since 1990 according to known estimates, land this is sargely due to falling rates of maternal deaths from direct obstetric causes [20]. Nonetheless, much of existing geographical coverage of basic and comprehensive emergency obstetric care (BEmOC and CEmOC) services, which are delivered largely through secondary and tertiary level facilities remains inadequate for the population's needs [23, 24].

The impact of severe weather on the poor road infrastructure has been described as a barrier for women to seek both antenatal and obstetric care in this region of Mozambique [25]. Flooding in the study area had also previously resulted in entire neighbourhoods being displaced or isolated from health care facilities, with pregnant women in some instances being cut off from emergency obstetric care for months [26]. While according to the authors' knowledge this is the first study in Mozambique to model geographical access to care based on travel time, previous studies have reported very long distances to access maternal health services and that this has an effect of elevating risk for adverse maternal outcomes [21, 25]. Nonetheless, in other sub-Saharan settings similar to Mozambique, it is known that some women travel for a very long time, sometime up to 2 days to access basic maternal care $[14,27]$.

\section{Methods}

\section{Study setting}

This study was conducted as part of the feasibility study in preparation for the Community Level Interventions in Pre-eclampsia Trial (CLIP, NCT01911494) in Mozambique [28]. CLIP is an ongoing community-based cluster randomized control trial, aimed at reducing all cause maternal and perinatal mortality and morbidity in the intervention areas. Ethics approval for CLIP was obtained from the CISM Institutional Review Board (CIBS-CISM), the Mozambique National Committee for Bioethics (CNBS) and the UBC Review Board, while approval for the mapping component was also acquired from the Simon Fraser University research ethics board.

\section{Data \\ Women of reproductive age population and pregnancies}

GPS points representing the households where all women of reproductive age in the study area lived were captured from the CLIP baseline census, and were used to determine the spatial population distribution. Characteristics of women of reproductive age within each household were also recorded and include pregnancies 


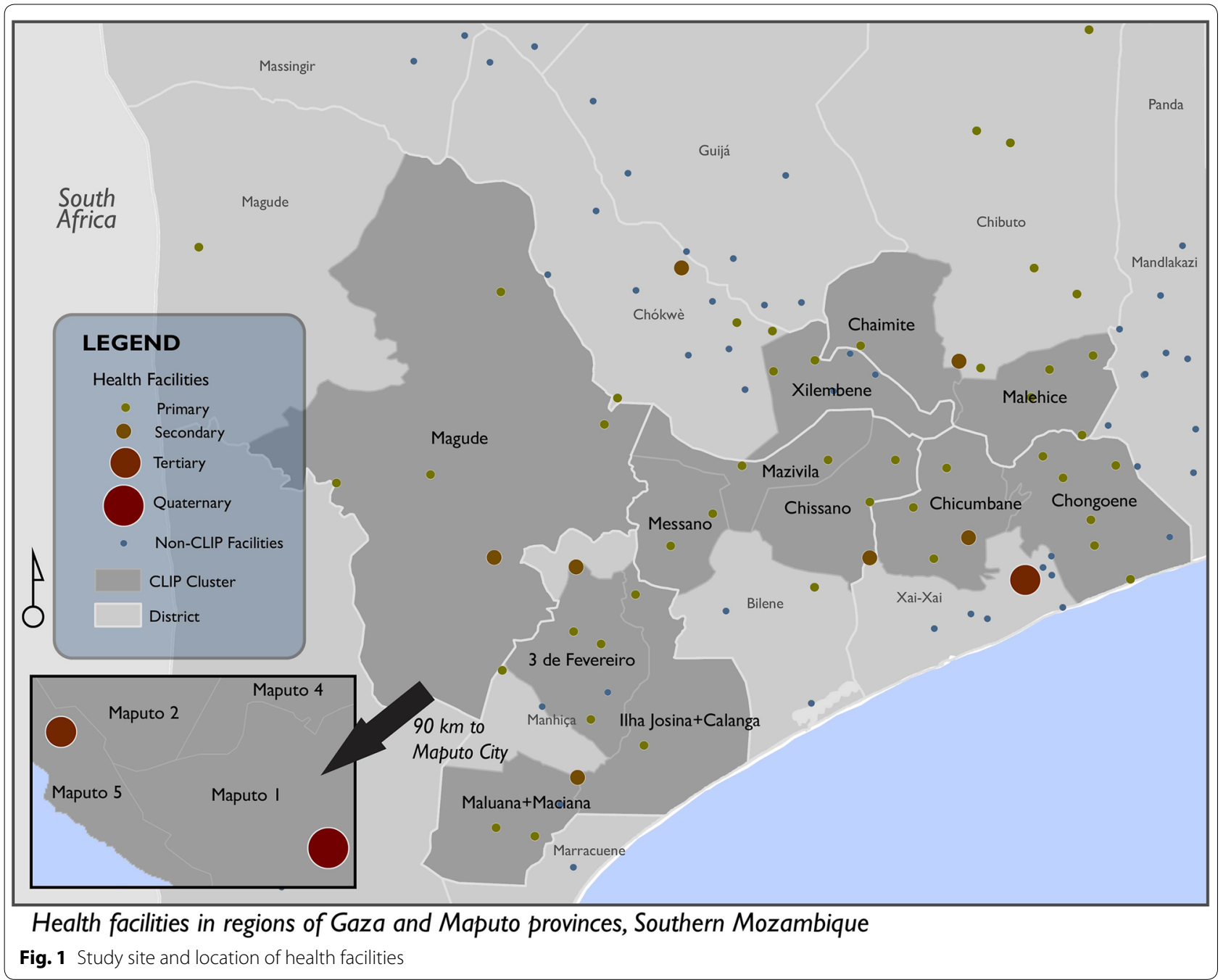

within the 12 months prior to the baseline census, completed pregnancies, pregnancy outcomes. These data were used to determine where populations that required access to maternal health services lived, as well as total number of pregnancies and women of reproductive age in different communities.

\section{Precipitation and floods}

To account for the impact of adverse weather events we sought to use empirical records of precipitation and floods (Fig. 2). Daily raster records of precipitation within the study area from March 2013 to October 2014 were acquired from the Famine Early Warning Systems Network [29]. These precipitation data are generated on a daily basis using satellite imagery and ground rain gauges [30,31]. This specific timeline was chosen to coincide with the timeline of the CLIP baseline census. Daily flood extent raster data for the same period was acquired from the Global Flood Observatory [32]. These are also generated on a daily basis from the MODIS satellite [33]. All the required precipitation and flood data were available except for 25 days of flood data and 4 days of precipitation data. These datasets were combined as a first step for creating an impedance surface used to estimate the effect of precipitation and floods on reducing access to health centres. Impedance surfaces are a grid based geographical representation of the ease of traversing through space, with high speed features such as highways, taking less time to traverse when compared to lower speed features such as footpaths for the same unit distance [34]. We assumed that flooded areas were not navigable by any means of transport, while road segments that had precipitation above $1 \mathrm{~mm}$, based on the rainy day threshold [35], would have had reduced maximum travel speeds, as expressed in Table 1.

A new geographical dataset of average weekly rainfall was created from the daily precipitation data. This shift in temporal scale was to account for the impact of 


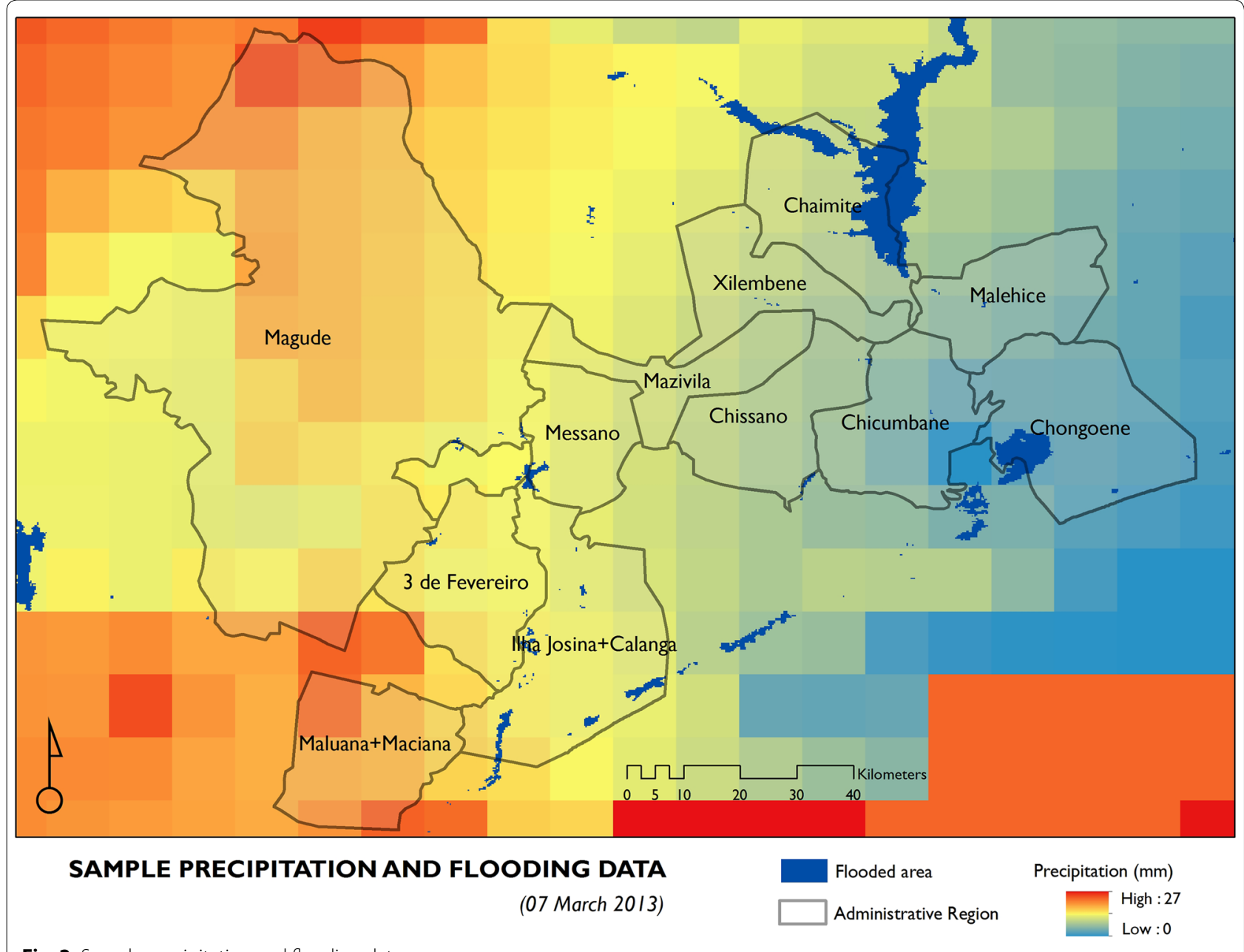

Fig. 2 Sample precipitation and flooding data

precipitation beyond the day it occurred. The $1 \mathrm{~mm}$ rainy day threshold (calculated as a weekly average) was used to determine whether a week was to be classified as a rainy week.

\section{Road network}

An initial road network dataset was provided by the Mozambique National Cartography and Remote Sensing Centre CENACARTA. These data constituted mainly of highways and a few major paved roads and were therefore highly inadequate for the community-level analysis that was intended for this study. We also considered open street map data [36] for the study areas but found it to be inadequate for modeling spatial access at the intended scale due to many missing roads at the community level. Data gaps were filled through a process of manual digitization of the missing roads from a high resolution Bing Maps satellite image service [37].
These roads were classified into highways, major paved roads, major unpaved roads, minor paved roads, minor unpaved roads and trails. A separate verification process was done by staff at CENACARTA and two other independent reviewers to identify and correct instances of misclassification, missing roads and other geometric errors.

Each road segment was assigned a value for travel time based on the length of the road segment and the speed limit. The speed limit was dependant on the road type, whether there was precipitation above the $1 \mathrm{~mm}$ weekly threshold, and if the road segment had been classified as being flooded at the time, with precipitation inducing a 20 and $30 \%$ reduction in the speed limit on paved roads and unpaved roads respectively. The estimates for the impact of precipitation on speed limits were derived from previous studies $[14,38-41]$ and are summarised in Table 1. 
Table 1 Impact of precipitation on speed limits

\begin{tabular}{|c|c|c|c|c|}
\hline \multirow[t]{2}{*}{ Precipitation } & \multirow[t]{2}{*}{ Road type } & \multicolumn{3}{|c|}{ Speed limits (km/hr) } \\
\hline & & Driving & Walking & Public transport \\
\hline \multirow[t]{6}{*}{ Dry weather } & Highway & 120 & 5 & 120 \\
\hline & $\begin{array}{l}\text { Paved major } \\
\text { road }\end{array}$ & 80 & 5 & 80 \\
\hline & $\begin{array}{l}\text { Unpaved major } \\
\text { road }\end{array}$ & 60 & 5 & 60 \\
\hline & $\begin{array}{l}\text { Paved minor } \\
\text { road }\end{array}$ & 40 & 4 & 4 \\
\hline & $\begin{array}{l}\text { Unpaved minor } \\
\text { road }\end{array}$ & 20 & 4 & 4 \\
\hline & Trail & 4 & 3 & 3 \\
\hline \multirow[t]{6}{*}{ Wet weather } & Highway & 96 & 4 & 96 \\
\hline & $\begin{array}{l}\text { Paved major } \\
\text { road }\end{array}$ & 64 & 4 & 64 \\
\hline & $\begin{array}{l}\text { Unpaved major } \\
\text { road }\end{array}$ & 42 & 4 & 42 \\
\hline & $\begin{array}{l}\text { Paved minor } \\
\text { road }\end{array}$ & 32 & 3 & 3 \\
\hline & $\begin{array}{l}\text { Unpaved minor } \\
\text { road }\end{array}$ & 14 & 3 & 3 \\
\hline & Trail & 2.8 & 2 & 2 \\
\hline Flood & \multicolumn{4}{|c|}{ Impassable (travel time $=99,999,999$ ) } \\
\hline
\end{tabular}

\section{Heath facilities}

The GPS coordinates of all public health facilities (Fig. 1) in the country were acquired from the Ministry of Health in Mozambique and research partners at Manhiça Research Centre. These facilities were classified into primary health centres (PHCs), secondary health facilities (SHF) and tertiary health facilities (THF). Data from a 2014 assessment of public health facilities that was conducted as part of the feasibility study for the CLIP trial were used to alter that classification of some of the facilities acquired from the Ministry, because the CLIP facility assessment had more recent results. None of the facilities outside the study area were reclassified due to a lack of recent data. Data on transport options available at each facility was also acquired from the CLIP facility assessment and used as the basis for deciding the most likely mode of transport that women would use to navigate through the facility referral chain.

\section{Modeling access to care Transport options}

Three modes of transports were considered for this project; walking, driving or using public transport. Both walking and driving were treated as single transport modes. However, for public transport we modelled travel assuming that women would walk to the nearest major road to access transport [25], and then drive from that point on. Therefore, for the public transport option we used the same speed limits for travelling through minor roads and trails as we did for walking, but changed the speed limits to be the same as driving for major roads and highways (see Table 1).

The likely scenarios of travel from the home to PHC and subsequent levels of the health care system were determined from the CLIP facility assessment and baseline census. During the facility assessment, information was recorded pertaining to the transport options available at each facility for patient referrals. Data on the personal transport options, as well as transport plans in the event of pregnancy related emergencies were also recorded for every household included in the baseline census and used to decide on the most likely characteristics of the women's journeys to access maternal care.

\section{Modeling spatio-temporal variation in access to care}

The process for modeling spatio-temporal variation in access to care is illustrated in Fig. 3. Access to care was modelled from the central location of the populated regions within all the neighbourhoods, instead of the commonly used centre of the actual neighborhood boundaries, which would include uninhabited regions including forests and agricultural zones. The model was developed to estimate travel times from these population centres of 417 neighbourhoods to the nearest health facility accounting for multiple modes of transport, and how this changed overtime. We assumed that most of the population would navigate through the referral chain in a hierarchical sequence; i.e. from home to PHC to SHF then THF. Most higher-level facilities will have lower level ones on premise (e.g. SHFs will normally have PHCs), thereby adopting multiple classifications. This design of the health care system therefore somewhat accounts for instances where people may bypass lower levels of the health care system by going directly to facilities that are closest to them.

The closest facility tool in the ArcGIS software was used to calculate the quickest route between neighborhoods and facilities based on the predefined speed limits along the road network dataset [42] for each of the 87 weeks of the study. Speed limits depended on the impedance values imposed on the road by the road type, precipitation and floods as illustrated in Table 1 . The service area tool [43] was used to create cartographically generalized visualizations illustrating the change in spatial access throughout the study at a macro scale.

Once the quickest travel times to the different level facilities for all travel scenarios were calculated for each week in the study timeline, the data was organized into 4 quartiles, for each week, indicating the travel times at the 25th, 50th, 75th and 100th percentiles for all 


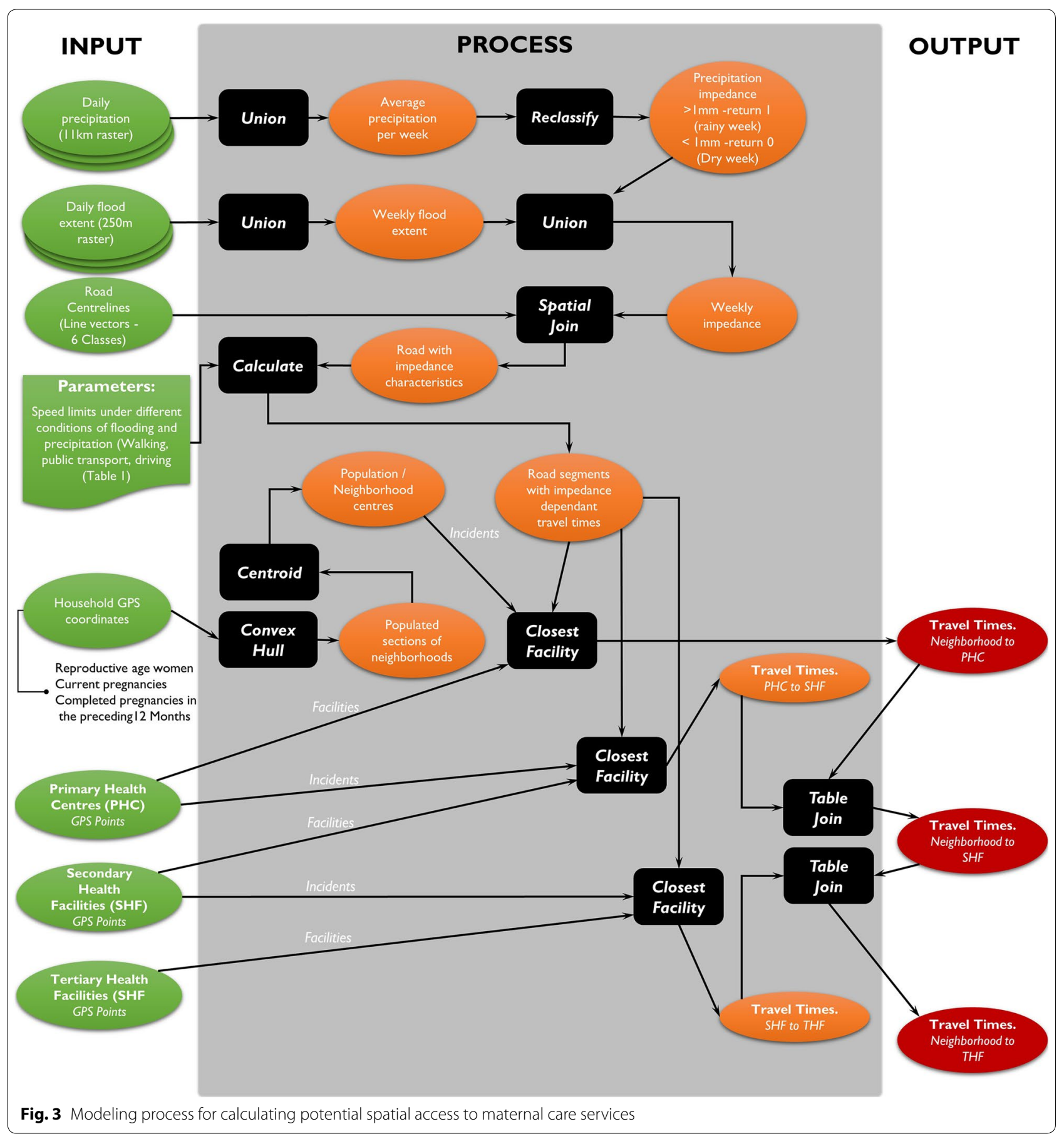

neighborhoods. This exploratory process was done to highlight the disparities that existed in travel times.

We also compared the travel times on the best day in the dry season and the worst day in the wet season to evaluate the extreme impact of precipitation and flooding on access to maternal care for women of reproductive age in general, and for those whom were likely to have been pregnant during these times. Given that it is impossible for women that were registered as having been pregnant during the study to have been pregnant for the entire timeline, we estimated the number of pregnancies at any given time assuming equal likelihood of being pregnant throughout the timeline. The 1- and 2-h travel time thresholds were used for primary care facilities and all other higher level facilities (SHF and THF) respectively, to differentiate women's access to basic 

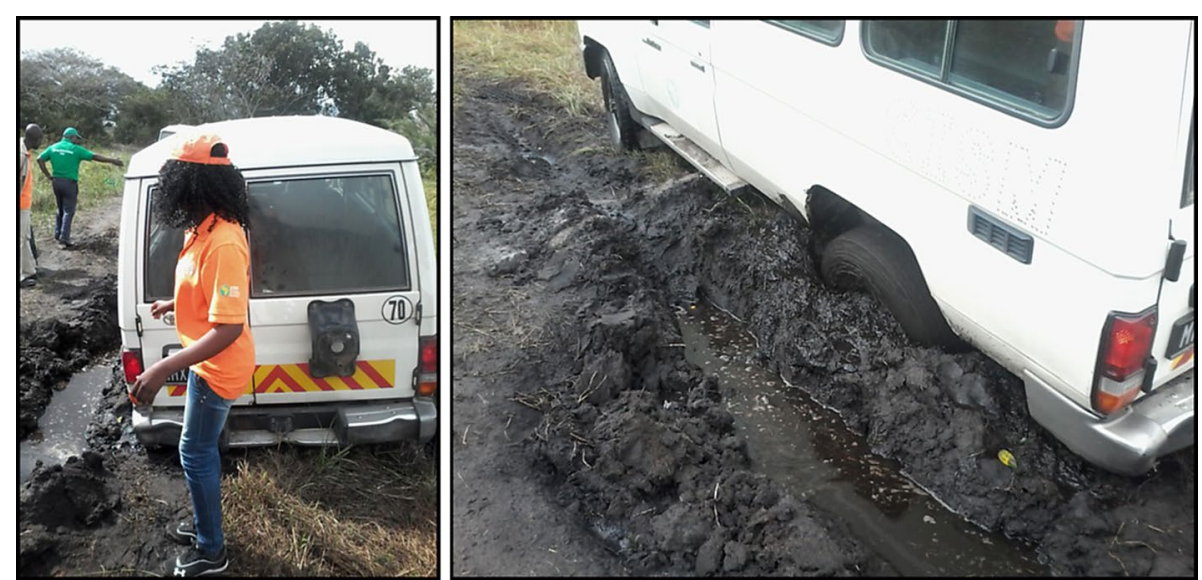

Fig. 4 Illustration of the effect of precipitation on hampering transport on minor unpaved roads—Photo taken by field team during a field visit to Calanga, in Maputo province

maternal and antenatal care from life-saving care delivered through BEmOC and CEmOC facilities at SHF and THF respectively.

\section{Determining isolation of communities}

Communities that would have been totally isolated from health care services because of flooding were also identified. Isolation was when the total travel time to the nearest facility was greater than $99,999,999 \mathrm{~min}$, which was the total time assigned for travelling through a flooded road segment that would have essentially been impassable using motorized transport or on foot. Approximately $85 \%$ of the roads in the study area are unpaved, with $75 \%$ of these being classified as minor unplanned roads [37]. The road infrastructure is thus typically hard to traverse in the wet season and not usable when flooded (Fig. 4). As the network algorithm used in this study identified the optimum routes with the quickest possible time for traversing from a community to a health facility, instances where travel times were greater than 99,999,999 indicated that no alternate route existed, meaning the road infrastructure could not be used.

\section{Transport options}

According to the baseline census, most women of reproductive age in the study area were likely to either walk or use public transport to travel to the nearest primary health centre (Table 2). This is since $70 \%$ of all households indicated not having private transport, and almost $72 \%$ of household indicated that pregnant women would nonetheless have access to transport funds when needed.

According to the facility assessment, most women were likely be driven from primary care facilities to higher level facilities. Women were either driven by ambulance from secondary to tertiary facilities, or by private cars from primary health centres to secondary facilities that are pre-arranged with car owners in the community (Table 2).

These findings led to a 6 scenario spatio-temporal model of access to care, that depicts the common modes of transport from the community to PHCs and through the facility referral network, including;

1. Walking to PHCs

2. Public transport to PHCs

3. Walking to PHCs and driving to SHFs (using ambulances)

4. Public transport to PHCs and driving to SHFs (using ambulances)

5. Walking to PHCs, driving to SHFs and driving to THFs (using ambulances)

6. Public transport to PHCs, driving to SHFs and driving to THFs (using ambulances).

\section{Results}

\section{Seasonal variation in travel times to health facilities}

Spatial access to health services generally decreases during the wet season for all modes of transport and to all level facilities due to the increase in travel times that are imposed by precipitation and flooding. At the peak of the dry season, $49 \%(n=38,887)$ of women of reproductive age included in the census lived within a 1-h walking time to the nearest PHC (Fig. 5). Approximately 6311 of women of reproductive age, would have been pregnant at the time, with $46 \%(n=2932)$ also living within 1 -h walk from a PHC. The population of women of reproductive age within a 1-h walking time to PHC dropped by 9 to $40 \%(n=31,716)$ while that of pregnant women dropped 
Table 2 Transport options available based on the CLIP baseline census and facility assessment

\begin{tabular}{|c|c|c|c|c|}
\hline Facility level & Transport options & $N$ & $\%$ & Most likely mode of transport \\
\hline \multirow[t]{8}{*}{ Community to $\mathrm{PHC}$} & Number of households that do not own private cars & 35,368 & 69.8 & \multirow{8}{*}{$\begin{array}{l}\text { Most women will either } \\
\text { 1. Walk to PHC (based on } 70 \% \text { not having } \\
\text { personal transport) } \\
\text { 2. Use public transport to } \mathrm{PHC} \text { (based on } \\
72 \% \text { having access to transport funds) }\end{array}$} \\
\hline & Number of households with a bicycle & 10,521 & 20.8 & \\
\hline & Number of households with a motorbike & 972 & 1.9 & \\
\hline & Number of households with a boat & 87 & 0.2 & \\
\hline & Number of households with a car & 2847 & 5.6 & \\
\hline & Number of households with other forms of transport & 784 & 1.5 & \\
\hline & $\begin{array}{l}\text { Number of households where pregnant women have } \\
\text { access to money for transport }\end{array}$ & 36,648 & 72.4 & \\
\hline & $\begin{array}{l}\text { Number of households that reported that they would get } \\
\text { transport help from neighbors or family }\end{array}$ & 6787 & 13.4 & \\
\hline \multirow[t]{3}{*}{$\mathrm{PHC}$ to SHF } & $\begin{array}{l}\text { PHCs with functional ambulance or other vehicle for } \\
\text { emergency }\end{array}$ & 2 & 4.0 & \multirow[t]{3}{*}{$\begin{array}{l}\text { Most women are likely to be driven from } \\
\text { primary to secondary facilities }\end{array}$} \\
\hline & PHCs with transport for patients referred to another facility & 43 & $93.0 \%$ & \\
\hline & $\begin{array}{l}\text { PHCs with access to an ambulance or other vehicle from } \\
\text { another facility }\end{array}$ & 44 & $96.0 \%$ & \\
\hline SHF to THF & $\begin{array}{l}\text { SHFs with functional ambulance or other vehicle for } \\
\text { emergency }\end{array}$ & 7 & $100.0 \%$ & $\begin{array}{l}\text { Most women are likely to be driven from } \\
\text { secondary to tertiary facilities }\end{array}$ \\
\hline
\end{tabular}

by 11 to $37 \%(n=2364)$ at any time during the wet season. The furthest communities were up to $7.9 \mathrm{~h}$ walking time to PHC during the dry season. However, this increased to $9.9 \mathrm{~h}$ at the peak of the wet season.

A similar pattern of reduced access is observed for travel to other level facilities for women that began their journeys with walking to PHCs. At the peak of the dry season, $64 \%(n=50,352)$ and $46 \%(n=36,151)$ of women of reproductive age lived within 2 -h travel time to the nearest SHF and THF, respectively, that offer life-saving maternal care. Approximately $61 \%$ of the women of reproductive age $(n=3840)$ and $43 \%(n=2722)$ of pregnant women also lived within 2-h travel time to SHF and THF, respectively. Populations of women of reproductive age living within 2-h from SHF and THF dropped to 53\% $(n=42,211)$ and $27 \%(n=21,764)$, respectively, while that of pregnant women dropped to $51 \%(n=3188)$ and $25 \%(n=1584)$, respectively, during the rainy season because of weather induced increases in travel in travel time.

The model scenarios involving the use of public transportation markedly reduce the travel times to all level facilities. At the peak of the dry season, $87 \%(n=69,299)$ of women of reproductive age lived within a 1-h travel time to the nearest $\mathrm{PHC}$ using public transport. Approximately $87 \%(n=5478)$ of pregnant women also lived within 1-h travel to the nearest PHCs. The population of women of reproductive age within 1-h travel time by public transport to PHC dropped by 5 to $82 \%$ ( $n=65,165)$ while that of pregnant women dropped by $6-80 \%(n=5110)$ at any time during the wet season. The furthest communities were up to $4.9 \mathrm{~h}$ of travel time to
PHC using public transport during the dry season. However, this increased to $6.6 \mathrm{~h}$ at the peak of the wet season.

At the peak of the dry season, 95\% $(n=75,281)$ and $75 \%$ ( $n=59,475)$ of women of reproductive age lived within 2-h travel time to the nearest SHF and THF respectively. Approximately $94 \%(n=5958)$ of the women of reproductive age and $73 \%(n=4618)$ of pregnant women also lived within a $2-\mathrm{h}$ travel time to SHF and THF, respectively. These populations of women of reproductive age living within two hours from SHF and THF dropped to $90 \%(n=71,208)$ and $51 \%(n=40,053)$, respectively, while that of pregnant women dropped to $88 \%(n=5572)$ and $48 \%(n=3004)$, respectively, during the rainy season.

There is a near exponential increase in travel times between the communities that are closest to health facilities compared to the ones that are the furthest (Fig. 5), indicating that huge disparities exist in access to maternal health services. For the furthest communities, there is a 2.1-hour increase in travel time to PHC, $2.7 \mathrm{~h}$ to SHF and 3.1 to THF for journeys that commences with walking to PHCs in the wet season. This increase in time is equivalent to walking approximately 10 extra kilometers to the nearest primary facility. Similarly, travel time increases by $1.7,2.5$ and $2.8 \mathrm{~h}$ to $\mathrm{PHC}$, SHF and THF respectively are also observed for the furthest communities when journeys commence with public transport.

The results suggest that the longer the travel time to a health facility the more likely populations are to be affected by precipitation or flooding (in and out of season)-hence the greater degree of fluctuation in travel times, particularly for the furthest communities in the 


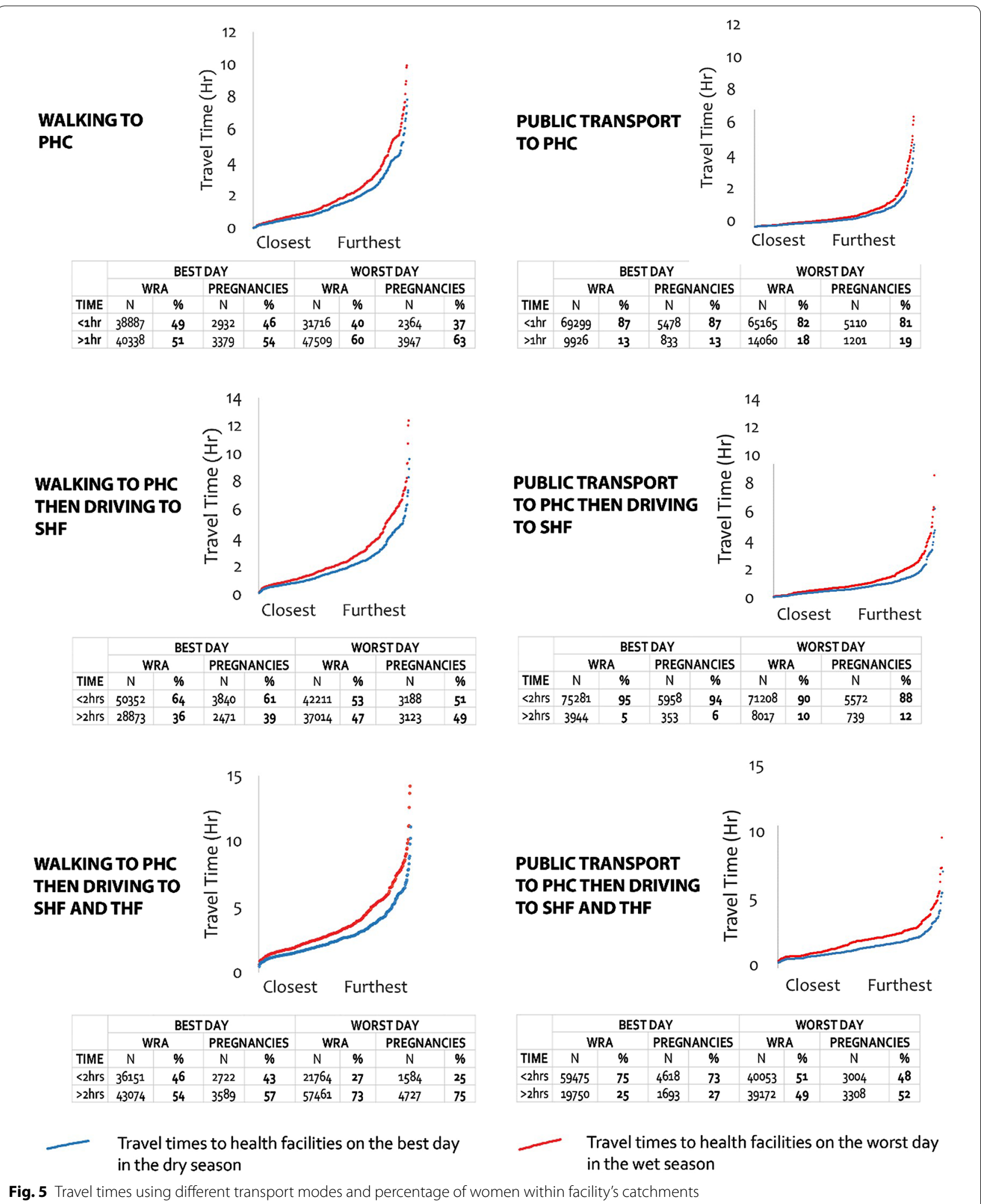


fourth quartile of travel times (Fig. 6). While there are more stable travel times to health facilities during the dry season, there are minor fluctuations during this time resulting from the few instances of rainfall in the dry season. Figure 6 illustrates the extent to which the furthest communities are disproportionately isolated (and potentially disproportionately more vulnerable) as the upper quartile of communities (red colour) has a much larger range when compared to the 1st, 2nd and 3rd quartiles for all modes of transport and facilities.

In terms of the place specific impact of severe wet weather on access, it appears Magude district, Ilha

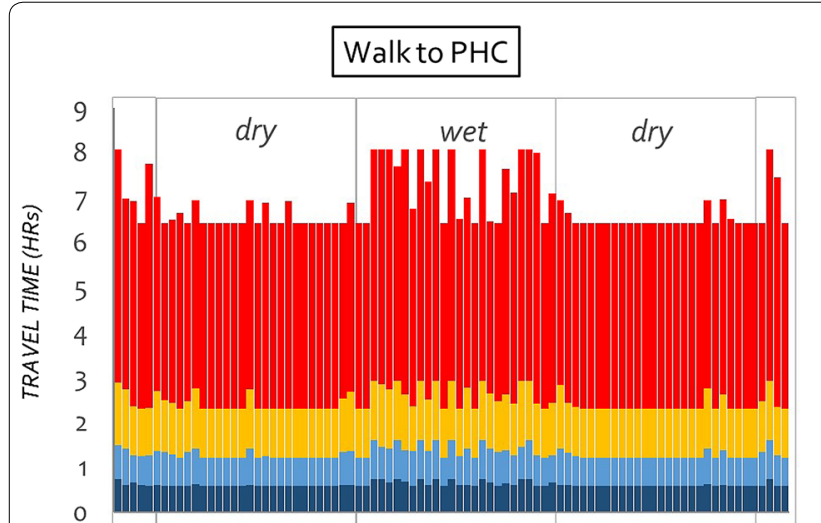

2013 Mar May Jul Sep Nov Jan Mar May Jul Sep 2014

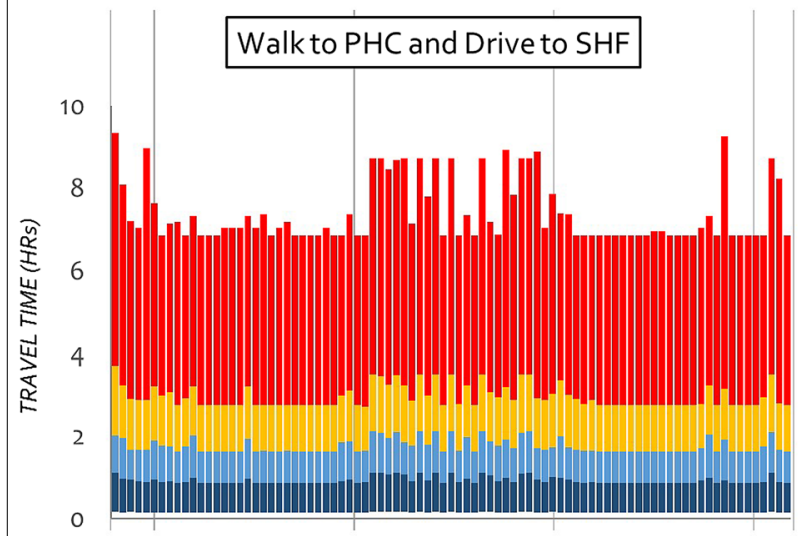

2013 Mar May Jul Sep Nov Jan Mar May Jul Sep 2014

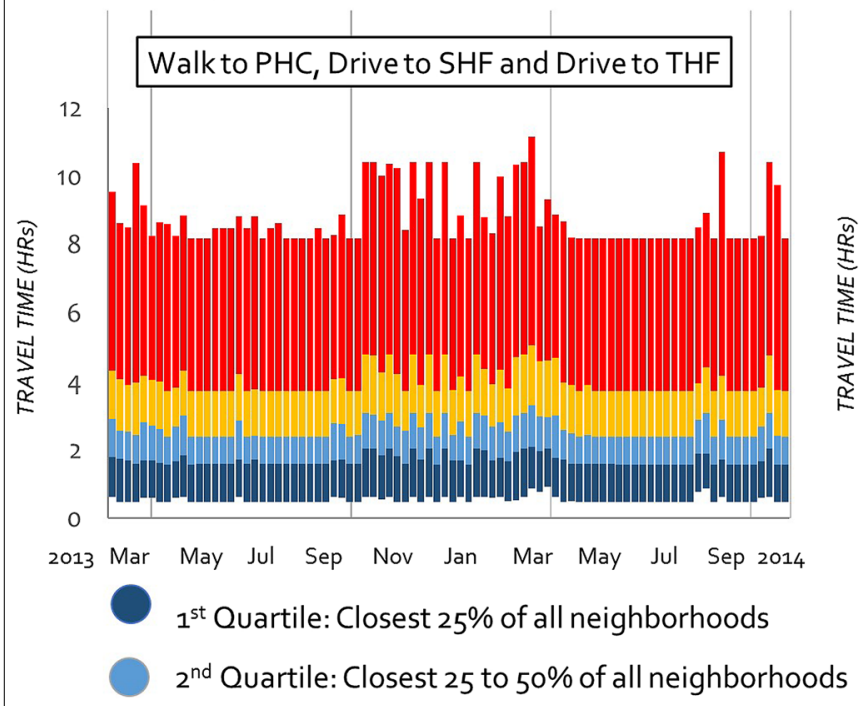

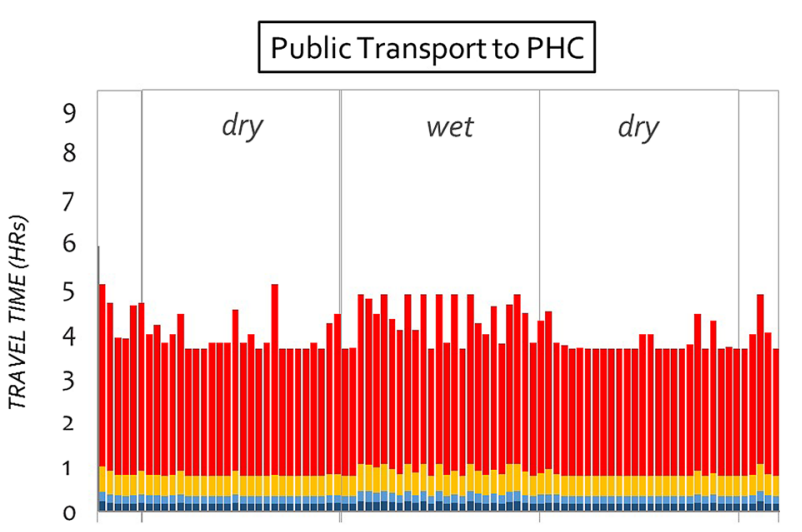

2013 Mar May Jul Sep Nov Jan Mar May Jul Sep 2014

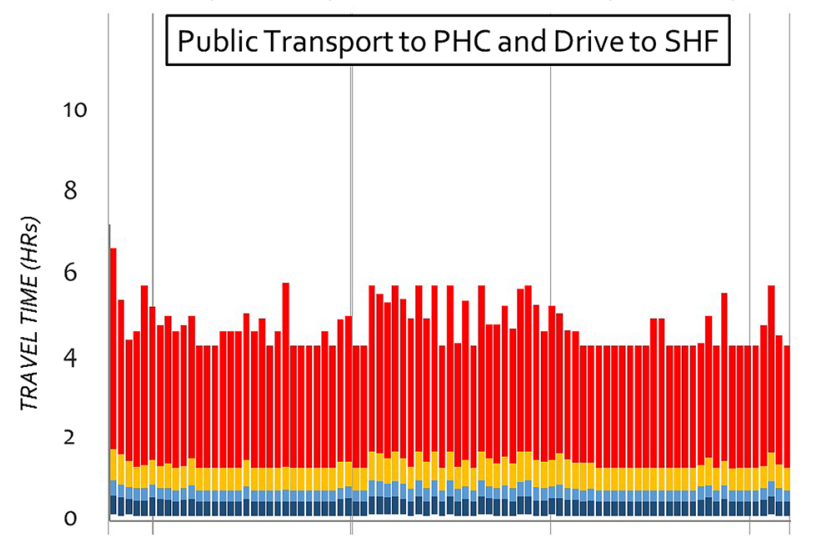

2013 Mar May Jul Sep Nov Jan Mar May Jul Sep 2014

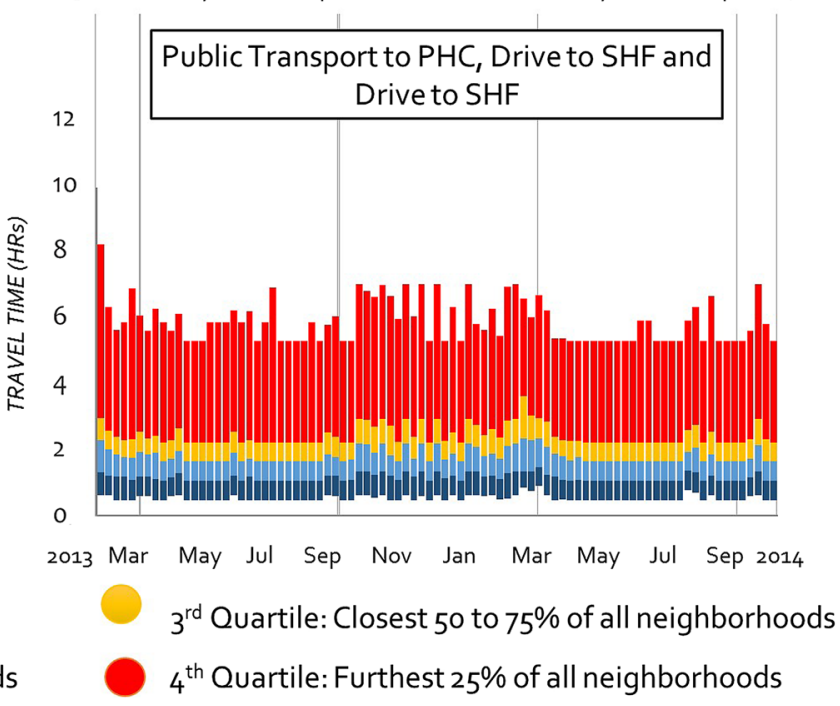

Fig. 6 Seasonal variation in travel times for different modes for the 17-month timeline 
Josina + Calanga and Chaimite regions are the areas most affected by the wet weather (Fig. 7), as they appear redder and yellower in B (wet weather) when compared to A (dry weather) for walking to PHCs. The reason for this is the low density of facilities as well as the poor road infrastructure in these regions. Populations in these regions will generally need to travel long distances on bad roads to access care. This is obviously aggravated by wet weather and flooding. The full set of maps indicating dry/wet weather differences in travel times have not been included but are available upon request. Some of spatio-temporal animations can be accessed at https://pre-empt.cfri.ca/monitoring/ mapping-outcomes-mothers-mom.

Thirteen of the 417 neighbourhoods were at some point completely isolated from health facilities (travel time $>99,999,999)$ during the study; 12 for one week and 1 for 16 weeks (Fig. 8). Most of these neighborhoods are unsurprisingly located in the regions of the study area shown in Fig. 7 to have been most severely affected by the wet weather.

\section{Discussion}

This paper describes a new approach for measuring and visualizing spatio-temporal access to maternal health services. To our knowledge this is the first time that empirical records of precipitation have been incorporated into modelling spatio-temporal variation in access to care. Specifically, this work extends the current models of geographical access to maternal care by accounting for the multiple transport options that characterize women's' journeys, and how their transit changes depending on season.

The transport information provided in the CLIP facility assessment and baseline census describe what a typical woman's journey from home to primary care facilities and through the rest of the health facility referral network looks like. While [34] demonstrated a model of spatial accessibility that accounts for mechanized and non-mechanized modes of transport, simulations of access were done for each mode in isolation. Other studies have projected travel times through the health facility referral chain in a hierarchical fashion similar to this study [27], but have overlooked the multiple transport options (walking, public transport, and use of ambulances) that characterize women's journeys. Our study explored travel times that result from the use of mixed transport modes through the various tiers of the health care system and advances spatial modeling of access to maternal care in a direction more suited for the daily realities of women in low- and middle-income countries where vulnerability to poor pregnancy outcomes is highest.
While a previous study [14] examined the potential impact of seasonality on access to maternal health services, our use of empirical daily records of precipitation and floods has demonstrated that the seasonal variation in access cannot simply be imagined through a dichotomous, and static lens of wet and dry seasons, as access continually fluctuates. The elements do not only slow down travel to health facilities, but in some instances can isolate whole communities from accessing these services [26]. The use of real weather records enhanced our understanding of how access to maternal care may be hampered. Media sources confirm that the communities identified as having been isolated because of floods, were actually flooded, in some instance resulting in the community members being evacuated [44-46].

While these results indicate a sizeable reduction in the number of women who live within 1-h of basic care (PHC) and 2-h from life-saving care (SHF and THF) because of precipitation and floods, the transport mode used has a much greater impact on increasing travel times to health facilities. For example, pregnant women living within an hour of primary care facilities are shown to increase by $41 \%$ when women access public transport from their community, compared to when they walk to PHCs to seek care (Fig. 5). A similar pattern exists for SHFs with an increase of $33 \%$ for pregnant women who live within 2 -h, resulting in $95 \%$ of all women living within 2-h of life-saving maternal care. This significant reduction in travel times because of access to public transport illustrates the potential impact of communitylevel transport related support for women needing to access maternal care, and further confirms the value of initiatives aimed at increasing access to transport as they will potentially greatly increase access to care both in the dry and wet seasons.

While the dominant view on geographical access to care assumes a need to measure distances or travel times from communities to health facilities, an emerging model of care in many low- and middle-income countries includes care by community health workers (CHWs) [47]. CHWs are "lay members of communities who work either for pay or as volunteers in association with the local health care system in both urban and rural environments and usually share ethnicity, language, socioeconomic status and life experiences with the community members they serve" [48]. These minimally trained workers extend the reach of basic health services in communities that are not well covered by health centres' [49]. The impact of flooding on hindering community health workers from accessing to pregnant women in need of services have been reported by [50]. The blend of weather sensitive spatio-temporal model of access with the upcoming strategies for reaching the most isolated populations with 

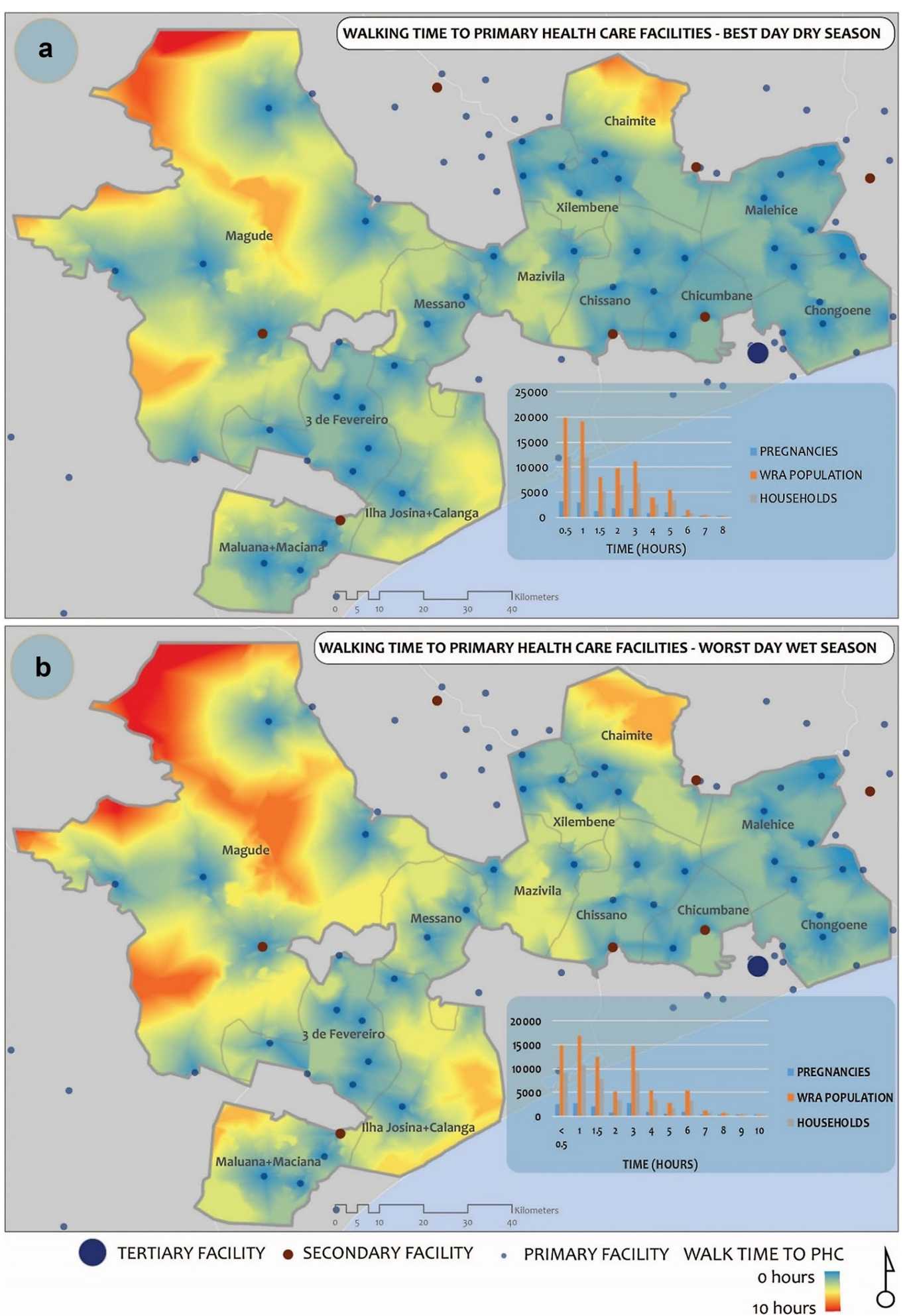

Fig. 7 A comparison of walking times to the nearest PHC on the best day in the dry season (a) and worst day in the wet season (b) 


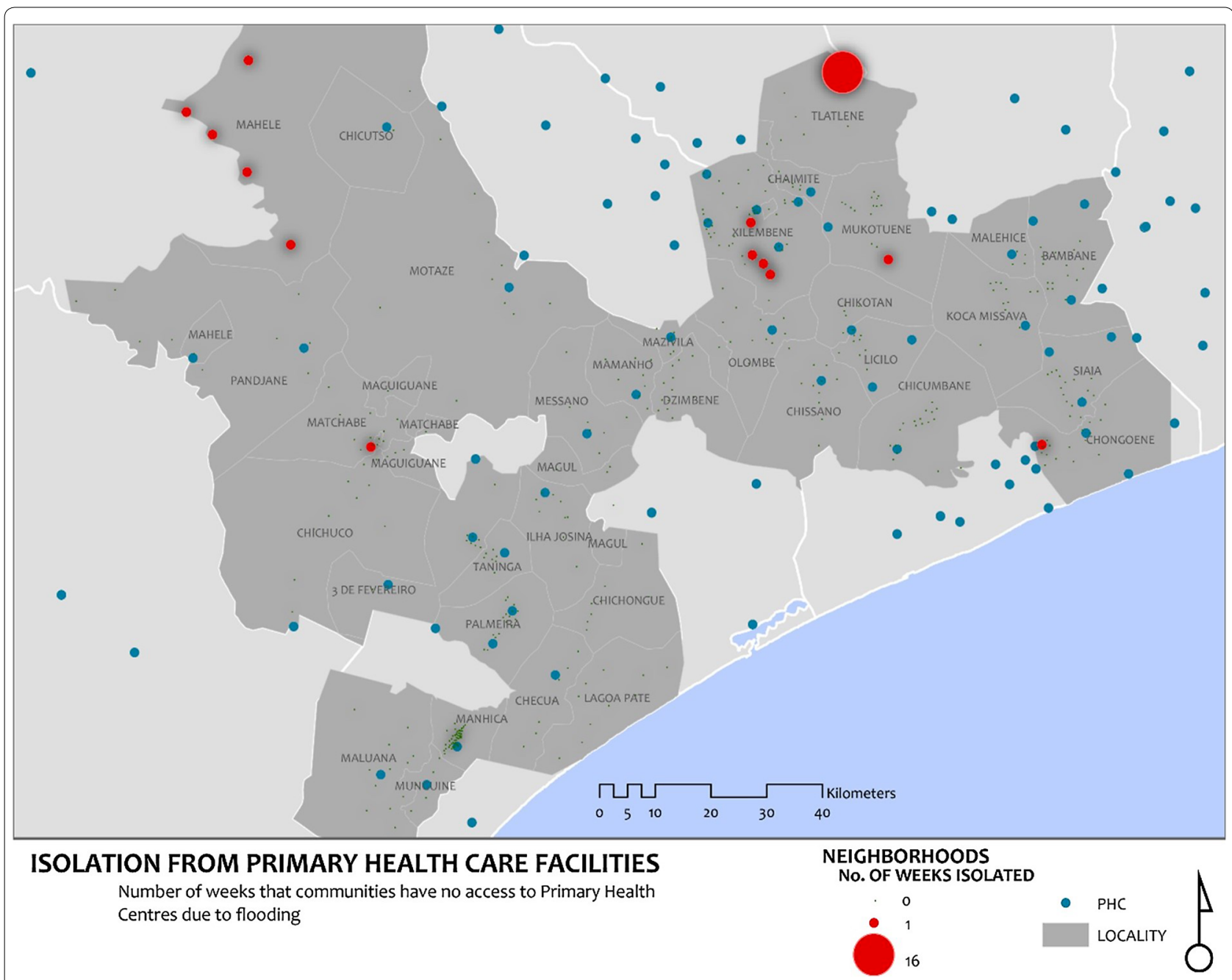

Fig. 8 Communities isolated from care as a result of flooding

health services through a mobile health force [51, 52] will potentially take to utility of spatio-temporal models of access beyond macro-planning of health services and make them operational on a daily basis at the community-level. The increased recognition of community level health surveillance, including pregnancy surveillance and mobile health technologies $[52,53]$ will set the context where these daily pictures of access could inform decisions by community health workers as they link communities to formal health services.

A limitation to our approach to modelling spatio-temporal access is that it does not account for wait times at facilities, as these data were not available. Wait times would provide a more accurate picture of how long it takes to navigate through the health care systems, accounting for both geographical and health services related delays. Including waiting times in the modelling process would be a step closer to modelling all three delays of triage, transport and treatment [54]. Further to that, in modelling the use of public transport, we did not account for time a woman may need to wait to get a vehicle once she gets to the main road. Waiting for transport is a known barrier to care seeking in the study area [25], thus making travel time estimate very conservative.

Another limitation for this study pertains to estimates for speed and travel time. While the ones used in this study have been adopted from previous studies on access to care, there is a lack of good evidence that these estimates are relevant for our study setting. There is also a lack of empirical data on the real extent to which precipitation reduces travel speed on different road types under study. Furthermore, safety concerns for women who may walk to seek emergency care at night, and the unavailability of public transport during evenings, have been previously noted as barriers for accessing to maternal care [15]. Future research is therefore needed on methods of 
generating empirical data for validating speed limits and how precipitation more precisely affects travel in different seasons and at different times of day.

The ideas and methods proposed in this paper can be translated to other health disciplines and settings where seasonal elements affect access to care. Similar problems of harsh weather impeding access to health care for geographically isolated regions in Aboriginal communities of Northern Canada [55]. Data show that women living in these communities are disproportionately more vulnerable and more likely to experience adverse maternal outcomes when compared with the rest of the Canadian population [4]. The proposed approach could be used to imagine new models of access that cater to the geography of, and temporal patterns in precipitation affecting women in these remote regions.

\section{Conclusions}

Models for spatio-temporal access that account for the daily realities of women's transport options in their communities are increasingly necessary. Understanding populations' geographical access to maternal health services and how it varies by season will enable health services planners to better identify populations that are underserved by their spatial configuration, and best increase access to health care. Flooding and heavy rainfall continue to be apparent characteristics of climate change, that are known to impede access to maternal care. This study highlights how to combine daily records on precipitations and floods to enhance the understanding of the seasonal variation in spatial access to maternal care in a way that has an impact, not only on long-term planning of maternal health services but potentially on improving daily planning concerning access to care at the facility and extending the reach of care to the community. Initiatives that for transport support at the community level will complement the understanding of these spatio-temporal dynamics to accessing maternal care and will help women get to health facilities quicker.

\begin{abstract}
Abbreviations
CENACARTA: National Cartography and Remote Sensing Centre; CHW: community health worker; CLIP: community level intervention for pre-eclampsia; FEWSNET: Famine Early Warning Systems Network; GIS: geographical information systems; GPS: global positioning system; PHC: primary health centre; SHF: secondary health facility; THF: tertiary health facility.
\end{abstract}

\footnotetext{
Author details

1 Department of Geography, Simon Fraser University, RCB7106 8888 University Drive, Burnaby, BC V5A156, Canada. ${ }^{2}$ Department of Surveying and Geomatics, Midlands State University, Gweru, Zimbabwe. ${ }^{3}$ Centro de Investigação em Saúde de Manhiça, Manhica, Mozambique. ${ }^{4}$ Department of Obstetrics and Gynaecology, University of British Columbia, Vancouver, Canada. ${ }^{5}$ Department of Obstetrics and Gynaecology, St George's, University of London, London, UK. ${ }^{6}$ Department of Medicine, University of British Columbia, Vancouver, Canada.
}

\section{Authors' contributions}

PTM, NS, PVD and TF made substantial contributions to conception and design of the project. FV, CS, KM, HED and ES led the acquisition of data in country data. PTM and NS led the analysis and were involved together with all the authors in the interpretation of the results. PTM, LM, TF, NS and MV made substantive contributions to writing the first complete version of the article, and all the authors were involved in revising it critically for important intellectual content. All authors read and approved the final manuscript.

\section{Acknowledgements}

The authors would like to acknowledge, Reason Mlambo, Yona Hagos and Mona Lee for their contributions to manual digitization of roads data, and Valódia Cármen Cufanhane and Antonio Maimbo from CENACARTA for volunteering to check the data and advise on data capture processes.

\section{Competing interests}

The authors declare that they have no competing interests.

\section{Availability of data and material}

All the street data that was used in this project can be available to anyone upon request. The flood data is available from the global flood observatory (http://floodobservatory.colorado.edu/), while the precipitation data is available from FEWSNET (ftp://ftp.cpc.ncep.noaa.gov/fews/fewsdata/africa/ arc2/geotiff/). The CLIP baseline data on pregnancies and reproductive age women's populations is not yet available in the public domain as the CLIP trial is still underway at the time of writing.

\section{Ethics approval and consent to participate}

Ethical approval for CLIP was obtained from the CISM Institutional Review Board (CIBS-CISM) and the UBC Review Board, while approval for the mapping component was acquired from the Simon Fraser University research ethics board.

\section{Funding}

This work was part funded by Grand Challenges Canada- Stars in Global Health program (Grant 0197) and was conducted as part of the PRE-EMPT (Pre-eclampsia/Eclampsia, Monitoring, Prevention and Treatment) initiative supported by the Bill \& Melinda Gates Foundation.

Received: 18 July 2016 Accepted: 8 December 2016

Published online: 13 January 2017

\section{References}

1. Johnson FA, Frempong-Ainguah F, Matthews Z, Harfoot AJ, Nyarko P, Baschieri A, et al. Evaluating the impact of the community-based health planning and services initiative on uptake of skilled birth care in Ghana. PLoS One. 2015;10(3):e0120556.

2. Brown CA, Sohani SB, Khan K, Lilford R, Mukhwana W. Antenatal care and perinatal outcomes in Kwale district, Kenya. BMC Pregnancy Childbirth. 2008;8(1):1.

3. Gage AJ, Guirlène Calixte M. Effects of the physical accessibility of maternal health services on their use in rural Haiti. Popul Stud. 2006;60(3):271-88.

4. Grzybowski S, Stoll K, Kornelsen J. Distance matters: a population based study examining access to maternity services for rural women. BMC Health Serv Res. 2011;11(1):147.

5. Shah N, Hossain N, Shoaib R, Hussain A, Gillani R, Khan NH. Socio-demographic characteristics and the three delays of maternal mortality. J Coll Phys Surg Pak. 2009;19(2):95-8.

6. Heaman MI, Sword W, Elliott L, Moffatt M, Helewa ME, Morris H, et al. Barriers and facilitators related to use of prenatal care by inner-city women: perceptions of health care providers. BMC Pregnancy Childbirth. 2015;15(1):1-13.

7. Osorio AM, Tovar LM, Rathmann K. Individual and local level factors and antenatal care use in Colombia: a multilevel analysis. Cad Saúde Pública. 2014;30(5):1079-92.

8. Olowonyo T, Oshin S, Obasanjo-Bello I. Registering in a health facility for delivery protects against maternal mortality in a developing country setting. J Obstet Gynaecol. 2005;25(7):638-41. 
9. Ebener S, Guerra-Arias M, Campbell J, Tatem AJ, Moran AC, Amoako Johnson F, et al. The geography of maternal and newborn health: the state of the art. Int J Health Geogr. 2015;14(1):1-10.

10. Makanga PT, Schuurman N, von Dadelszen P, Firoz T. A scoping review of geographic information systems in maternal health. Int I Gynecol Obstet. 2016;134(1):13-7.

11. Kruk ME, Freedman LP. Assessing health system performance in developing countries: a review of the literature. Health Policy. 2008;85(3):263-76.

12. Grzybowski S, Kornelsen J, Schuurman N. Planning the optimal level of local maternity service for small rural communities: a systems study in British Columbia. Health Policy. 2009:92(2):149-57.

13. Tatem AJ, Campbell J, Guerra Arias M, Bernis L, Moran A, Matthews Z. Mapping for maternal and newborn health: the distributions of women of childbearing age, pregnancies and births. Int J Health Geogr (Internet). 2014:13. http://dx.doi.org/10.1186/1476-072X-13-2.

14. Blanford JI, Kumar S, Luo W, MacEachren AM. It'sa long, long walk: accessibility to hospitals, maternity and integrated health centers in Niger. Int J Health Geogr. 2012;11(1):1-15.

15. Munjanja SP, Magure T, Kandawasvika G. Geographical access, transport and referral systems. In: Maternal and perinatal health in developing countries; 2012. p. 139-54.

16. Subramaniam V. Seasonal variation in the incidence of preeclampsia and eclampsia in tropical climatic conditions. BMC Womens Health. 2007;7(1):18.

17. Okafor UV, Efetie ER, Ekumankama O. Eclampsia and seasonal variation in the tropics-a study in Nigeria. Pan Afr Med J. 2009;2(1):7.

18. Mwaniki P, Kabiru E, Mbugua G. Utilisation of antenatal and maternity services by mothers seeking child welfare services in Mbeere District, Eastern Province, Kenya. East Afr Med J. 2002;79(4):184-7.

19. Porter G. Transport services and their impact on poverty and growth in rural sub-Saharan Africa: Literature review. Report to the Africa Community Access Programme, London. 2012.

20. Bailey PE, Keyes E, Moran AC, Singh K, Chavane L, Chilundo B. The triple threat of pregnancy, HIV infection and malaria: reported causes of maternal mortality in two nationwide health facility assessments in Mozambique, 2007 and 2012. BMC Pregnancy Childbirth. 2015;15(1):1.

21. David E, Machungo F, Zanconato G, Cavaliere E, Fiosse S, Sululu C, et al. Maternal near miss and maternal deaths in Mozambique: a crosssectional, region-wide study of 635 consecutive cases assisted in health facilities of Maputo province. BMC Pregnancy Childbirth. 2014;14(1):1-8

22. World Health Organization, UNICEF. Trends in maternal mortality: 1990 to 2013: estimates by WHO, UNICEF, UNFPA, The World Bank and the United Nations Population Division: executive summary (Internet). 2014 http://apps.who.int/iris/bitstream/10665/112682/2/9789241507226_eng. pdf?ua=1. Cited 20 Oct 2016.

23. Galukande M, von Schreeb J, Wladis A, Mbembati N, de Miranda $H$, Kruk ME, et al. Essential surgery at the district hospital: a retrospective descriptive analysis in three African countries. PLoS Med. 2010;7(3):e1000243.

24. Pereira C, Cumbi A, Malalane R, Vaz F, McCord C, Bacci A, et al. Meeting the need for emergency obstetric care in Mozambique: work performance and histories of medical doctors and assistant medical officers trained for surgery. BJOG Int J Obstet Gynaecol. 2007;1 14(12):1530-3.

25. Munguambe K, Boene H, Vidler M, Bique C, Sawchuck D, Firoz T, et al. Barriers and facilitators to health care seeking behaviours in pregnancy in rural communities of southern Mozambique. Reprod Health. 2016;13(1):83-97.

26. Jamisse L, Songane F, Libombo A, Bique C, Faúndes A. Reducing maternal mortality in Mozambique: challenges, failures, successes and lessons learned. Int J Gynecol Obstet. 2004;85(2):203-12.

27. Bailey PE, Keyes EB, Parker C, Abdullah M, Kebede H, Freedman L. Using a GIS to model interventions to strengthen the emergency referral system for maternal and newborn health in Ethiopia. Int J Gynecol Obstet Internet Int Fed Gynecol Obstet (Internet). 2011;115. http://dx.doi. org/10.1016/j.jigo.2011.09.004.

28. Khowaja AR, Qureshi RN, Sawchuck D, Oladapo OT, Adetoro OO, Orenuga EA, et al. The feasibility of community level interventions for pre-eclampsia in South Asia and Sub-Saharan Africa: a mixed-methods design. Reprod Health. 2016;13(1):1-15.

29. FEWSNET. Famine Early Warning Systems Network—Precipitation GIS Data (Internet). 2016. ftp://ftp.cpc.ncep.noaa.gov/fews/fewsdata/africa/ arc2/geotiff/. Cited 17 Jan 2016.
30. Herman A, Kumar VB, Arkin PA, Kousky JV. Objectively determined 10-day African rainfall estimates created for famine early warning systems. Int J Remote Sens. 1997;18(10):2147-59.

31. Novella N, Thiaw W. Africa rainfall climatology version 2. Wash Natl Ocean Atmospheric Adm. 2012.

32. Global Flood Observatory. Dartmouth flood observatory—space-based measurement, mapping, and modeling of surface water for research, humanitarian, and water management applications (Internet). 2016. http://floodobservatory.colorado.edu/. Cited 17 Jan 2016.

33. Brakenridge R, Anderson E. MODIS-based flood detection, mapping and measurement: the potential for operational hydrological applications. In: Marsalek J, Stancalie G, Balint G, editors. Transboundary Floods: Reducing Risks Through Flood Management (Internet). Dordrecht: Springer Netherlands; 2006. p 1-12. http://dx.doi.org/10.1007/1-4020-4902-1_1

34. Gething PW, Johnson FA, Frempong-Ainguah F, Nyarko P, Baschieri A, Aboagye P. Geographical access to care at birth in Ghana: a barrier to safe motherhood. BMC Public Health (Internet). 2012;12. http://dx.doi. org/10.1186/1471-2458-12-991.

35. Zhang X, Alexander L, Hegerl GC, Jones P, Tank AK, Peterson TC, et al. Indices for monitoring changes in extremes based on daily temperature and precipitation data. Wiley Interdiscip Rev Clim Change. 2011;2(6):851-70.

36. Open Street Map. openstreetmap (Internet). 2016. https://www.openstreetmap.org/\#map=9/-24.8864/33.5413.

37. Makanga PT, Schuurman N, Sacoor C, Boene H, von Dadelszen P, Firoz T. Guidelines for creating framework data for GIS analysis in low- and middle-income countries. Can Geogr. 2016; In Press.

38. Rakha H, Farzaneh M, Arafeh M, Hranac R, Sterzin E, Krechmer D. Empirical studies on traffic flow in inclement weather. Virginia Tech Transportation Institute; 2007.

39. ACIS. Decree-Law $1 / 2011$ of 23 March-THE ROAD TRAFFIC CODE (Internet). 1/2011. 2011. http://www.mcli.co.za/mcli-web/downloads/docs/ acis_road_code_decree_law_1-2011.pdf.

40. Alegana VA, Wright JA, Pentrina U, Noor AM, Snow RW, Atkinson PM. Spatial modelling of healthcare utilisation for treatment of fever in Namibia. Int J Health Geogr. 2012;11(1):1.

41. Hranac R, Sterzin E, Krechmer D, Rakha HA, Farzaneh M, Arafeh M. Empirical studies on traffic flow in inclement weather. 2006.

42. ESRI. Closest facility analysis (Internet). 2016. http://desktop.arcgis.com/ en/desktop/latest/guide-books/extensions/network-analyst/closestfacility.htm.

43. ESRI. Service area analysis (Internet). 2016. http://desktop.arcgis.com/en/ desktop/latest/guide-books/extensions/network-analyst/service-area.htm.

44. World Health Organization. Post Flood Health Assessment-Report Gaza Province-Mozambique (Internet). 2013. http://www.who.int/hac/crises/ moz/sitreps/mozambique_health_assessment_30january2013.pdf.

45. United Nations Office of the Coordination of Humanitarian Affairs. MOZAMBIQUE: Flood Displaced Accommodation Centres as of 26 January 2013 (Internet). 2013. http://reliefweb.int/sites/reliefweb.int/ files/resources/Mozambique\%20Flood\%20Displaced\%20Accommodation\%20Centres\%20as\%20of\%2026\%20January\%202013.pdf.

46. Mozambique News Agency. Incomati flood laps at edges of EN1 (Internet). 2014. http://www.poptel.org.uk/mozambique-news/newsletter/ aim481.html\#story3.

47. Lehmann U, Sanders D. Community health workers: what do we know about them? The state of the evidence on programmes, activities, costs and impact on health outcomes of using community health workers. World Health Organ. 2007;2:1-42.

48. Goodwin K, Tobler L. Community health workers. Communities. 2008;1:2.

49. Tulenko K, Mgedal S, Afzal MM, Frymus D, Oshin A, Pate M, et al. Community health workers for universal health-care coverage: from fragmentation to synergy. Bull World Health Organ. 2013;91(11):847-52.

50. Teela KC, Mullany LC, Lee Cl, Poh E, Paw P, Masenior N, et al. Communitybased delivery of maternal care in conflict-affected areas of eastern Burma: perspectives from lay maternal health workers. Soc Sci Med. 2009;68(7):1332-40.

51. Bhutta ZA, Reddy S. Achieving equity in global health: so near and yet so far. J Am Med Assoc (Internet). 2012;307. http://dx.doi.org/10.1001/ jama.2012.4659.

52. von Dadelszen P, Ansermino JM, Dumont G, Hofmeyr GJ, Magee LA, Mathai $\mathrm{M}$, et al. Improving maternal and perinatal outcomes in the 
hypertensive disorders of pregnancy: a vision of a community-focused approach. Int J Gynecol Obstet. 2012;119:S30-4.

53. Braun R, Catalani C, Wimbush J, Israelski D. Community health workers and mobile technology: a systematic review of the literature. PLoS One. 2013;8(6):e65772.
54. Thaddeus S, Maine D. Too far to walk: maternal mortality in context. Soc Sci Med (Internet). 1994;38:1091. doi:10.1016/0277-9536(94)90226-7.

55. Sevean P, Dampier S, Spadoni M, Strickland S, Pilatzke S. Patients and families experiences with video telehealth in rural/remote communities in Northern Canada. J Clin Nurs. 2009;18(18):2573-9.

\section{Submit your next manuscript to BioMed Central and we will help you at every step:}

- We accept pre-submission inquiries

- Our selector tool helps you to find the most relevant journal

- We provide round the clock customer support

- Convenient online submission

- Thorough peer review

- Inclusion in PubMed and all major indexing services

- Maximum visibility for your research

Submit your manuscript at www.biomedcentral com/submit
() Biomed Central 